\title{
Blood pressure and its significance in childhood
}

\author{
RONALD M. LAUER \\ M.D. \\ William R. Clarke \\ Ph.D. \\ LINDA K. RAMES \\ Division of Pediatric Cardiology, Department of Pediatrics, University of Iowa Hospitals, \\ Iowa City, Iowa 52242, U.S.A.
}

\begin{abstract}
Summary
Hypertension is an important accelerator of the atherosclerotic process. Detection in childhood may be important although longitudinal data are lacking of the prognosis of blood pressure measurement in childhood through adult life. The blood pressure of children should be measured.

In populations where salt intake is high, values for blood pressure increase with age. Populations who eat small quantities of salt are relatively free from hypertension. There is an epidemiological argument for limiting salt intake in children.

There are few data to indicate the level of blood pressure in children which should be treated. Children's blood pressures are labile and elevated levels are sustained only in a small minority. In these secondary causes, advice should be sought. In subjects with extreme persistent hypertension drug therapy should be considered; in subjects with values of blood pressure not so extremely raised surveillance should be maintained to prevent the development of sustained hypertension.
\end{abstract}

\section{Introduction}

The high frequency of hypertension in adults, its predictive and causative relationship to stroke, coronary heart disease and renal disease, and the improvement in morbidity and mortality affected by drug therapy for hypertension documented by the Veterans Administration Study Group (1970), has resulted in a consideration of the significance of blood pressure measurement in children by a Task Force on Blood Pressure Control in Children (1977).

In early childhood, blood-pressure levels are much lower than those that are predictive of future disease in adults. Few children whose blood pressures were measured in early childhood have been followed longitudinally to late adult life to see the relationship of early childhood blood pressure levels to the adult onset of coronary heart disease or stroke. There is also no information that relates to the efficacy of lowering children's blood pressure levels. Thus, the if predictive significance of children's blood pressure measurements at present must be extrapolated from information that is less direct.

Some features that relate to children's blood 8 pressure levels will now be reviewed. Also, a clinical 을 strategy will be presented that may be used by physicians when dealing with individual children.

\section{Measurement of blood pressure}

Blood pressure can be measured with relative ease $\vec{\varphi}$ in children over 3 years of age and should be red corded as part of a routine physical examinatio The child may be in a seated or recumbent position depending on the normal reference tables to be used. The blood pressure should be measured by means $\overline{0}$ of a blood pressure cuff whose bladder width covers $\stackrel{\circ}{\circ}$ at least two-thirds of the upper arm and is suffi- $\varnothing$ ciently long to encompass most of the circumference $\overrightarrow{\overrightarrow{0}}$ of the arm without overlapping, as suggested by 3 Kirkendall et al. (1967). The first, fourth and fifth Korotkoff sounds should be recorded. In children, frequently the Korotkoff sounds can be heard when the pressure in the cuff is completely deflated. For 3 . this reason, the fourth Korotkoff sound is suggested $\frac{5}{3}$ as a better index of diastolic pressure in children. The relationship of the Korotkoff vascular sounds to intravascular pressures has been studied by Moss $₹$ and Adams (1968) and Holland and Humerfelt $\frac{\text { 의 }}{5}$ (1964). There is a high correlation between systolic $>$ pressures and a lower relationship with diastolic pressures. Despite their less-than-perfect relation- N ships, pressures measured by the usual clinical ${ }^{\circ}$ techniques have wide application and in adults $\tilde{O}^{\circ}$ have predictive value for future coronary heart ${ }_{\omega}^{N}$ disease, stroke and renal disease.

Systolic blood pressure can be accurately measuredo in infants with a Doppler device. Hernandez, Goldring and Hartman (1970) have shown good corre-? lation between pressures obtained intra-arterially and 7 those recorded by the Doppler method. Hernandez, Meyer and Goldring (1975) have indicated that this 

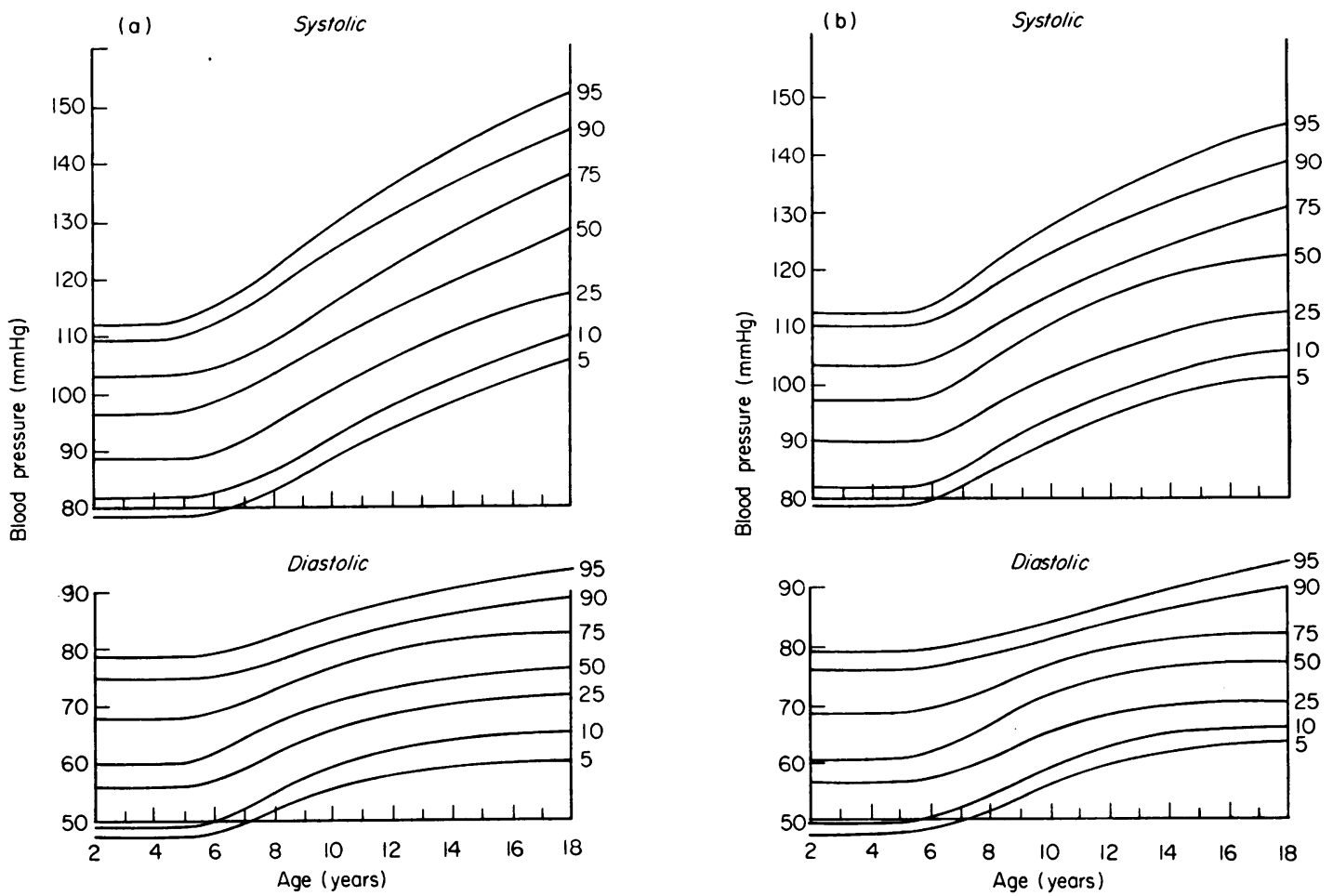

FIG. 1. Selected centiles of seated blood pressures in (a) boys and (b) girls obtained from pooled data obtained in 11614 children aged 2 to 18 years from Miami (Florida), Muscatine (Iowa) and Rochester (Minnesota). (From the Report of the Task Force on Blood Pressure Control in Children (1977) reproduced by kind permission of the editor of Pediatrics). As with height and weight centile charts, these charts are not meant to be used for single diagnostic evaluations, but as a convenient way to chart blood pressures in a single child over time.

is a reproducible and reliable method of bloodpressure measurement in infants. This instrument, because of its ease of use, should be available where infants and young children require careful observation such as operating rooms, recovery rooms, newborn nurseries, and intensive care areas.

\section{Normal values of blood pressure}

Normal values of seated blood pressure in relation to age and sex have been established in children in Rochester (Minnesota), Miami (Florida) and Muscatine (Iowa) and are shown in the report of the Task Force on Blood Pressure Control in Children (1977). Seated blood pressures of children in Muscatine (Iowa) have also been described by Lauer et al. (1975) and in Bogalusa (Louisiana) by Voors et al. (1976). Londe and Goldring (1968) have established normal supine values for children 3-15 years of age. All these cross-sectional surveys have shown a continuous rise in blood pressure with age from eally school age with an acceleration of this rise during the adolescent years. Fig. 1 shows seated blood pressure centiles obtained from children ages 2-17 years. It was suggested by the Task Force on Blood Pressure Control in Children (1977) that all children older than 3 years of age should have their blood pressures measured and plotted on such grids as part of their normal continuing health care.

\section{Need for repeated blood pressure measurements}

Serial determinations of blood pressure are necessary in order to document persistent elevations of blood pressure. After screening over 300 high school students, Kilcoyne, Richter and Alsup (1974) found that the overall prevalence of systolic hypertension ( $>140 \mathrm{mmHg}$ ) fell from 5.4 to $1.2 \%$ and diastolic hypertension ( $>90 \mathrm{mmHg}$ ) fell from 7.8 to $2.4 \%$ on repeat screening. In Muscatine (Iowa), Rames et al. (1977), after screening 6600 predominantly white school children, identified $13 \%$ of this population as having systolic and/or diastolic blood pressures $>$ the 95th centile or $>140 / 90 \mathrm{mmHg}$. After repeated examinations of these subjects, less than $1 \%$ maintained pressures at these levels. Fixed hypertension in the school-age 
population is thus not a common finding, and the need for taking several blood pressure readings over a period of time before considering a child to have an elevated blood pressure is most important.

\section{Tracking of blood pressure}

An important epidemiological consideration is whether or not blood pressures taken in childhood are predictive of blood pressure levels in adulthood. If this were so then future hypertensives could be identified in childhood.

In the Evans County (Georgia) study by Heyden et al. (1969), $11 \%$ of 435 adolescents were found to be hypertensive (>140 $\mathrm{mmHg}$ systolic and/or $>90 \mathrm{mmHg}$ diastolic) in 1961. Seven years later, thirty of this group were re-evaluated. Sustained hypertension developed in five, and six had sustained hypertension with vascular complications. Two of the black females in this group died from cerebral haemorrhage, both verified at post-mortem.

Zinner et al. (1974) followed 609 children 6-18 years of age over a 4-year period. Of eighty-eight children with initial systolic pressures greater than 1 standard deviation unit above the mean, $65 \%$ had positive scores at follow-up and $70 \%$ of children with initial systolic scores less than 1 standard deviation unit below the mean had negative scores at follow-up. These data suggest that stratification of blood pressure within peer groups begins and is detectable in childhood.

Buck (1973) followed children from ages 5 to 12 years and found those whose systolic and diastolic blood pressures were greater than the 90th centile at the age of 5 years showed a statistically significant elevation of both systolic and diastolic pressures at 12 years of age when compared to age-matched controls.

Over a 5-year period in Muscatine (Iowa), 1953 children have had their blood pressures measured on three occasions. The overall correlation coefficient for systolic blood pressure from the first to the second reading was 0.36 and from the first to the third reading, 0.36 . The correlation coefficient for diastolic blood pressure from the first to the second reading was 0.17 and from the first to the third reading was $0 \cdot 21$. These observations by Clarke $e t$ al. (1976) show that although there is a relationship between the blood pressures obtained in early childhood and those obtained 5 years later, there is marked variability in blood pressure such that it is difficult to predict who will be a future hypertensive. They indicate the need for repeated measurements of children's blood pressures to establish those that have consistent elevations of blood pressure.

In the Thousand Aviator study of Oberman et al. (1967), young men with an entry mean age of 24 years were followed-up for 24 years. Of those men whose systolic blood pressure was in the uppero quintile at the age of 24 years, $40 \%$ remained at that level over the ensuing 24 years. Thus, in young adults, prediction of future blood pressures may be? better than in childhood.

\section{Familial aggregation of blood pressure}

Observations have shown that hypertension max, occur in several members of a family. Ayman (1972) reported elevated blood pressure in $28 \%$ of children in families with one hypertensive paren? and $41 \%$ of children with two hypertensive parents as well as in $65 \%$ of adult siblings of hypertensive patients. Miall et al. $(1962,1967)$ showed that ther is a familial resemblance of blood pressure in adults. and their first degree relatives. In a study of 350 siblings of 178 patients with severe hypertension Platt (1963) found a greater incidence of hypertensiono in the siblings as compared to the general populationi Johnson, Epstein and Kjelsberg (1965) in a study of children in Tecumseh (Michigan), found distince resemblances in the values between parent's andchildren's blood pressures over the entire distribution of blood pressure. The correlation coefficient be tween parents and chldren, although significant, was of a low order. Between siblings they found $\bar{a}$ o similar low correlation.

Zinner, Levy and Kass (1971) found a cluster⿳亠口冋่ of blood pressures of children 2-14 years of with the blood pressures of their siblings and of theie mothers. The correlation coefficients for systolian blood pressure of sib-sib and mother-child wero 0.34 and 0.16 respectively. The clustering effect was measurable at all levels of blood pressure. In the Evans County Prevalence study by Heyden et al (1969) similarities for first degree relatives, as measured by correlation coefficients, are of the same. order of magnitude in blacks and whites and of the same order of magnitude as reported in other populations. A similar degree of familial aggre $\frac{3}{3}$ gation between a child and his siblings and parents. was shown to exist as early as 2 months of age by Klein et al. (1975).

The degree of these relationships suggest that blood pressure is affected by environmental of genetic factors but the low order of relationship is. not strong enough to allow the identification of hypertensive families by the examination of one family member.

\section{Electrolytes and hypertension}

Epidemiological studies in Polynesia, Micronesixo Africa and South America by Oliver, Cohen anष Neel (1975), Kohlstaedt et al. (1958), Dahl and Love $(1954,1957)$, and Truswell et al. (1973) have suggested that populations who eat small quantities of sale are relatively free of hypertension. Analysis of the? 
diets among such groups by Dahl (1958) showed a daily intake of not more than $5 \mathrm{~g}$ of salt with some eating less than $1 \mathrm{~g}$.

In South American Indians who excrete $<2 \mathrm{mg}$ of sodium over $24 \mathrm{hr}$, none had a systolic pressure greater than $120 \mathrm{mmHg}$ as found by Oliver et al. (1975) while in the Northern Japanese farmers who excrete $>10 \mathrm{~g}$ of sodium $/ 24 \mathrm{hr}, 84 \%$ had systolic pressures $>140 \mathrm{mmHg}$ as reported by Tahahosi, Sashi and Takeda (1957). In their salt-feeding experiments in rats, Meneely and Dahl (1961) found there was an 8-month difference between median duration of survival in the high salt rats and the controls. If one were to translate this figure to man, this would be equivalent to a difference in the median duration of life of about 24 years. When potassium chloride was added to the diet there were no changes in the hypertensigenic action of the extra sodium chloride but there was an improvement in survival. The median duration of life was increased by 7 months and yet throughout life the blood pressure persisted at intermediate levels, just as in animals who received no extra potassium chloride. Thus, there is an indication that, among animals and humans consuming large amounts of salt, hypertension is common.

Lauer et al. (1976) studied the salt preferences and taste threshold for salt in children, 33 whose mean blood pressures were $<$ the 5 th centile, 33 whose pressures were between the 47.5 and 52.5 centiles, and 33 whose pressures were $>$ the 95th centile. There were no significant differences in preference and threshold between the three groups. These data suggest that if salt intake is a determining factor in the level of children's blood pressures, it is not related to their preference or ability to taste salt. The question of whether children with higher pressures consume more salt for reasons unrelated to preference or threshold, is as yet unsettled.

Interestingly, Oliver et al. (1975) found that in the adolescent years, some populations who consume a low salt diet fail to show a further rise in pressures while populations with salt freely available show increasing pressures with age. Populations who move from a low salt environment to a high salt environment show an increase of blood pressure with age similar to those populations who have always lived with easy access to salt. These observations suggest that the chronic intake of salt in amounts well in excess of requirements may play a primary role in the pathogensis of hypertension in man. Since salt appetite is unrelated to salt requirements and is perhaps a learnt phenomenon, one wonders if salt should be restricted from infancy in an effort to decrease the incidence of hypertension in young adulthood. It may be easier to restrict salt intake in the young rather than reverse salt appetite at a later age.

\section{A working definition of hypertension}

Because blood pressure levels in childhood have not been studied for their predictive value in adult life, hypertension is most difficult to define. In childhood, systolic or diastolic blood pressures greater than the 95th centile on three or more occasions several months apart have been suggested by the Task Force on Blood Pressure Control in Children (1977) as a definition for clinical action. If the blood pressure continues to remain elevated to these levels, the patient should be evaluated to exclude secondary causes of hypertension. In a study of school children at Muscatine (Iowa), Rames et al. (1978) noted that the causes of secondary hypertension frequently could be detected early in a screening process. Initial examinations of these children revealed obesity, urinary symptoms, use of oral contraceptives, and coarctation of the aorta. Only $0.6 \%$ had secondary hypertension; $0.3 \%$ were obese with hypertension and $0.2 \%$ were lean with no identifiable causes for hypertension.

\section{Treatment}

There are few data which allow judgment about the level of blood pressure that should be treated in children. It is clear that children's blood pressures are extremely labile and elevated pressures will not be persistent in the majority of cases. Only patients with elevated blood pressures documented by multiple observations over a period of time should be considered for therapy and then only after causes for secondary hypertension have been eliminated.

For subjects with unexplained hypertension, factors that should be influenced by changes in life style include salt intake, obesity and cigarette smoking. Although there is suggestive evidence that excess sodium intake may play a primary role in the genesis of hypertension, available evidence does not warrant general recommendations regarding dietary habits in the population at large. However, individuals with persistent hypertension might benefit by salt restriction to less than $5 \mathrm{~g} /$ day.

Drug therapy itself is not without potential hazards. While serious adverse pharmacological effects have not been described at present, there has never been an adequate evaluation of children receiving antihypertensive agents for prolonged periods.

The Task Force on Blood Pressure Control in Children (1977) has recommended that only subjects with extreme persistent hypertension (diastolic pressures $>90 \mathrm{mmHg}$ between 3 and 12 years of age or $>110 \mathrm{mmHg}$ for children over 12 years of age) should be considered for drug therapy after thorough examination. Subjects with blood pressures less than these levels but with values persistently greater than the 95th centile for age should be maintained under 
surveillance because of the concern that they may develop higher blood pressures as they mature.

\section{Acknowledgment}

Supported by a Specialized Center for Research Grant in Atherosclerosis (HL-14230) and a research grant (HL20124) from the National Heart, Lung and Blood Institute of the National Institutes of Health, Department of Health, Education and Welfare, U.S.A.

\section{References}

Ayman, D. (1972) Heredity in arteriolar (essential) hypertension: A clinical study of the blood pressure of 1,524 members of 277 families. Archives of Internal Medicine, 53, 792.

BuCk, C.W. (1973) Persistence of elevated blood pressure first observed at age 5. Journal of Chronic Diseases, 26, 101.

Clarke, W.R., Woolson, R., Schrott, H., Wiebe, D. \& LAUER, R.M. (1976) Tracking of blood pressure, serum lipids and obesity in children: The Muscatine Study. Circulation, 54 (Suppl. II), 23.

DAHL, K.L. (1958) Medical progress. Salt intake and salt need. New England Journal of Medicine, 258, 1152.

DAHL, K.L. \& LOVE, R.A. (1954) Evidence for relationship between sodium (chloride) intake and human essential hypertension. Archives of Internal Medicine, 94, 525.

DAHL, K.L. \& LOVE, R.A. (1957) Etiological role of sodium chloride intake in essential hypertension in humans. Journal of the American Medical Association, 164, 391.

Hernandez, A., Goldring, D. \& HaRTman, A.F. (1970) Measurement of blood pressures in infants and children by the Doppler ultrasonic technique. (Abstract): Midwest Society of Pediatric Research.

Hernandez, A., Meyer, D.A. \& Goldring, D. (1975) Blood pressure in neonates. Contemporary Obstetrics/ Gynecology, 5, 34.

Heyden, S., Bartel, A., hames, C. \& McDenough, J. (1969) Elevated blood pressure levels in adolescents, Evans Country, Georgia, seven year follow-up of 30 patients and 30 controls. Journal of the American Medical Association, 209, 1683.

Holland, W.W. \& Humerfelt, S. (1964) Measurement of blood pressure: Comparison of intra-arterial and cuff values. British Medical Journal, 2, 1241.

Johnson, B.C., EPSTEIN, F.H., \& KJElsberG, M.O. (1965) Distributions and familial studies of blood pressure and serum cholesterol levels in a total community - Tecumseh, Michigan. Journal of Chronic Diseases, 18, 147.

Kilcoyne, M.M., Richter, R.W. \& AlsuP, P.A. (1974) Adolescent hypertension. I. Detection and prevalence. Circulation, 50, 750.

Kirkendall, W.M., Burton, A.C., Epstein, F.H. \& Freis, E.D. (1967) Recommendations for human blood pressure determinations by sphygmomanometers. Circulation, 36, 980.

Klein, B.E., Hennekens, C.H., Jesse, M.J., Gourley, J.E. \& BLUMENTHAL, S. (1975) Longitudinal studies of blood pressure in offspring of hypertensive mothers. In: Epidemiology and Control of Hypertension (Ed. by Paul, O.), p. 387. Stratton Medical Books, New York.

Kohlstaedt, K.C., Moser, M., Francis, T., Neel, J. \& MOORE, F. (1958) Panel discussion on genetic and environ- mental factors in human hypertension. Circulation, $17 \stackrel{\Phi}{\mathrm{Q}}$ 728.

Lauer, R.M., Connor, W.E., Leaverton, P.E., Reiter, M.A. \& CLARKE, W.R. (1975) Coronary heart disease risk factors in school children: The Muscatine Study. Journal of Pediatrics, 86, 697.

LAUER, R.M., FILER, L.J., JR, REITER, M.A. \& ClARKe, W.R.o (1976) Blood pressure, salt preference, salt threshold and $\overline{\bar{\omega}}$ relative weight. American Journal of Diseases of Children, $\overrightarrow{\mathbb{D}}_{\mathrm{Q}}$ 130, 493.

LONDE, S. \& GolDRING, D. (1968) Blood pressure standards? for normal children as determined under office conditions." Clinical Pediatrics, 7, 400.

MENeELY, G.R. \& DAHL, K.L. (1961) Electrolytes in hypertension: the effects of sodium chloride. The evidence from $\vec{\omega}$ animal and human studies. Medical Clinics of Northo America, 45, 271.

Miall, W.R., Heneage, P., Heneage, P., Khosla, T. LOVELL, H.G. \& MOORE, F. (1967) Factors influencing. the degree of resemblance in arterial pressure of close relatives. Clinical Science, 33, 271.

Miall, W.R., Kass, E.H., LiNG, J. \& Stuart, K.L. (1962)గ్రి Factors influencing arterial pressure in the general population in Jamaica. British Medical Journal, 2, 497.

Moss, A.J. \& ADAms, F.H. (1968) Heart Disease in Infants, Children and Adolescents, p. 60. Williams \& Wilkins Co.,, New York.

Oberman, A., Lane, N.E., Harlan, W.R., Graybiel, A. $\vec{Z}$ \& Mitchell, R.E. (1967) Trends in systolic blood pressure in thousand aviator cohort over a twenty-four year period. Circulation, 36, 812.

Oliver, W.J., COHEN, E.L. \& NeEL, J.V. (1975) Blood pres - $\overrightarrow{0}$ sure, sodium intake and sodium related hormones in Yanomano Indian, a 'no-salt' culture. Circulation, $\mathbf{7}, \infty$ 146.

Platt, R. (1963) Heredity in hypertension. Lancet, i, 899.

RAMES, L.K., ClaRKE, W.R., CONNOR, W.E., REITER, M.A. \& LAUER, R.M. (1978) Normal blood pressures and the evaluation of sustained blood pressure elevation in childhood: The Muscatine Study. Pediatrics, 61, .

TAHAHOSI, E., SASHI, N. \& TAKEDA, J. (1957) The geographic distribution of cerebral hemorrhage and hypertension in $\overrightarrow{\bar{O}}$ Japan. Human Biology, 29, 139.

TASK ForCe ON BloOD Pressure Control in ChILdRen (1977) National Heart, Lung and Blood Institute and National High Blood Pressure Education Program. Pediatrics, 59, 797.

Truswell, A.S., Kennelly, B.M., Hansen, J.D.L \& Lee, R.B. (1972) Blood pressure of Kung bushmen in Northern Botswana. American Heart Journal, 84, 5.

VETERANS ADMINISTRATION CoOPERATION Study Group ON ANTIHYPERTENSIVE AGENTS (1970) Effects of treatment on morbidity in hypertension. II. Results in patients with diastolic blood pressure averaging 90 through $114 \mathrm{mg} \mathrm{Hg}$.응 Journal of the American Medical Association, 213, 1143.

Voors, A.W., Foster, T.A., Frerichs, R.R., Weber, L.S. $\frac{D}{8}$ \& BERENSON, G.S. (1976) Studies of blood pressures in children, ages 5-14 years, in a total biracial community. The Bogalusa Heart Study. Circulation, 54, 319.

ZINNER, S.H., LEVY, P.S. \& KASS, E.H. (1971) Familial aggregation of blood pressure in childhood. New England $\bigcirc$
Journal of Medicine, 284, 401.

Zinner, S.H., Martin, L.F., Sachs, R., Rosner, B. \& Kass, E.H. (1974) A longitudinal study of blood pressure in childhood. American Journal of Epidemiology, 100, 437. 